$\begin{array}{ll} & \text { Etnográfica } \\ \text { etnográfica } & \text { Revista do Centro em Rede de Investigação em }\end{array}$

Antropologia

vol. 20 (2) | 2016

Vol. $20(2)$

\title{
Carregado em saia de encantado: transformação e pessoa no terecô de Codó (Maranhão, Brasil)
}

Person and transformation in Codó's terecô (Maranhão, Brazil)

\section{Martina Ahlert}

\section{(2) OpenEdition}

\section{Journals}

\section{Edição electrónica}

URL: https://journals.openedition.org/etnografica/4276

DOI: 10.4000/etnografica.4276

ISSN: 2182-2891

\section{Editora}

Centro em Rede de Investigação em Antropologia

\section{Edição impressa}

Data de publição: 1 junho 2016

Paginação: 275-294

ISSN: 0873-6561

\section{Refêrencia eletrónica}

Martina Ahlert, «Carregado em saia de encantado: transformação e pessoa no terecô de Codó

(Maranhão, Brasil)», Etnográfica [Online], vol. 20 (2) | 2016, posto online no dia 29 junho 2016,

consultado o 09 fevereiro 2022. URL: http://journals.openedition.org/etnografica/4276 ; DOI: https:// doi.org/10.4000/etnografica.4276

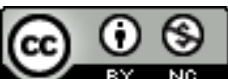

Etnográfica is licensed under a Creative Commons Attribution-NonCommercial 4.0 International License. 


\section{Carregado em saia de encantado: transformação e pessoa no terecô de Codó (Maranhão, Brasil)}

\section{Martina Ahlert}

Este artigo discorre sobre as diversas modalidades de relação entre pais de santo e entidades em uma religião afro-brasileira chamada terecô, encontrada no interior do estado do Maranhão, Brasil. O texto inicia com as primeiras manifestações das entidades (encantados) na vida de uma pessoa, que acontecem por intermédio de aflições e doenças. Explora ainda o estabelecimento das relações com as entidades que se desenvolvem durante a trajetória de vida de um terecozeiro. Por fim, pensa os momentos de afastamento entre esses seres, chamando atenção para o consumo dos corpos e o envelhecimento dos pais e mães de santo.

PALAVRAS-CHAVE: terecô, etnografia, corpo, religiões afro-brasileiras, relações.

Person and transformation in Codó's terecô (Maranhão, Brazil) - This paper discusses various forms of relationship between "saint-fathers" and entities of terecô, an Afro-Brazilian religion found in the countryside of the state of Maranhão, Brazil. The article begins with the first appearance of the invisible "charmed" entities (encantados) in one's life, which transpire through afflictions and diseases. Following that, it explores the establishment of relationships with such entities as unfolded throughout the life of a terecô practitioner. Finally, it explores the moments of separation between entities and practitioners, calling attention to the weariness/collapse of bodies and the ageing of "saint-fathers" and "saint-mothers".

KEYWORDS: terecô, ethnography, body, Afro-Brazilian religions, relationships.

AHLERT, Martina (ahlertmartina@gmail.com) - Departamento de Sociologia e Antropologia, Universidade Federal do Maranhão, Brasil. 
AS COSTAS, PERNAS E BRAÇOS DE LUIZA NÃO APRESENTAM O DESEMpenho de outrora. Com mais de 70 anos, as transformações corporais, fruto de seu envelhecimento, não falam apenas do passar dos anos, mas também das atividades de chefia de sua tenda de terecô. ${ }^{1} \mathrm{O}$ terecô é a mais popular das denominações dadas à religião afro-brasileira encontrada em diferentes cidades do Brasil, mas que se afirma provir do município maranhense de Codó - cidade onde Luiza vive e é mãe de santo, no nordeste do país. Chamado ainda de tambor da mata, encantaria de Barba Soeira, brinquedo de Santa Bárbara ou verequete, o terecô é de provável origem banta (com elementos jeje e nagô) e tem como língua ritual o português (Eduardo 1948; Barros 2000; M. Ferretti 2001 ; Araújo 2008). Nele estão presentes entidades chamadas de encantados - seres que tiveram vida terrena e entretanto desapareceram (enquanto pessoas) deste plano de existência. Quando sumiram, passaram a habitar um entremundo chamado de encantaria, de onde vêm para dançar, trabalhar, dar conselhos e fazer atendimentos.

Nas tendas de pais e mães de santo, como a de Luiza, os encantados dançam a partir dos pontos que os invocam. Em outros momentos, são recebidos fora dos rituais, em situações ordinárias ou ainda quando solicitados para consultas e atendimentos. Entende-se que existam, no Maranhão, três grupos de encantados: os de água doce, encontrados especialmente na região da Baixada; os de água salgada, do tambor de mina, da capital do estado; e os encantados da mata, que formariam a principal família da região de Codó, chefiada por Légua Boji Buá da Trindade (Eduardo 1948; M. Ferretti 2001; Barros 2000; Cunha 2013; Ahlert 2013). Seu Légua ou Velho Légua é a entidade de maior renome na cidade e possui uma família numerosa, com mais de quinhentos membros (seus filhos e filhas, netos e netas, irmãos e irmãs). Sua personalidade, assim como a de alguns de seus parentes, é marcada por uma postura irreverente e provocadora, pelo apego ao consumo de bebida alcoólica e pela propensão a causar confusão. Seus relacionados, assim como ele próprio, são associados ao período da escravidão, à mata e à lida com animais.

Nos salões codoenses, os encantados da mata dividem espaço com outras entidades, como orixás, caboclos e caboclos de pena, voduns do tambor de mina maranhense, ${ }^{2}$ pretos velhos, pombagiras, etc. O terecô está combinado, de diversas maneiras, com a umbanda e com o candomblé, cujas primeiras tendas foram construídas em Codó no século passado, provavelmente nas décadas de 1930 e 1980. As diferenças entre entidades e denominações religiosas na cidade, assim como suas combinações e articulações, não têm fronteiras

l O termo tenda é utilizado como sinônimo de salão, barracão ou terreiro - espaço de culto e celebração ritual.

2 Para saber mais sobre as diferenças entre essas entidades, ver o trabalho de Mundicarmo Ferretti $(2000)$ 
claras que seja possível conceituar de forma generalista. Em minha concepção, a partir da convivência em campo, essas variações estão relacionadas com a trajetória de cada pessoa e também com a forma com a qual uma entidade se apresenta a ela. ${ }^{3}$ Atualmente, segundo pesquisadores locais, existem cerca de 250 tendas chefiadas por pais e mães de santo em Codó, sejam elas de terecô, umbanda ou candomblé, além de quartos altares que fazem das casas relicários e espaços de cura. ${ }^{4}$

Dona Luiza há muitos anos "baia" ou "brinca" terecô. Seu corpo, bronzeado do sol escaldante da região, franzino e ligeiramente encurvado, foi (e ainda é) o vetor por excelência das relações mantidas e reafirmadas com um conjunto de encantados por ela recebidos. Foi a partir de seu percurso que busquei problematizar as relações estabelecidas entre pessoas e encantados, dando ênfase à transformação desses diferentes seres em um plano temporal não linear. Tenho, nesse sentido, uma dupla orientação: por um lado, desejo pensar as primeiras manifestações das entidades na vida de um sujeito - que, na maioria dos casos, acontecem na infância - e, a partir delas, discorrer sobre as formas de relação estabelecidas entre pessoas e encantados. Por outro lado, estou interessada nos momentos de afastamento entre uns e outros, que nas histórias que aqui conto acontecem com o envelhecimento e com experiências associadas ao mesmo. Essa dupla perspectiva está conjugada com a preocupação teórico-metodológica de pensar, simetricamente, entidades e pessoas, suas possibilidades de afeto e participação umas nas outras (Goldman 1984, 1987, 2014; Birman 2005; Rabelo 2014).

Minha escrita nasce de uma etnografia, resultado da pesquisa de campo realizada durante o meu doutorado em Antropologia Social, entre 2010 e 2011, quando pude viver em Codó por cerca de um ano. Depois desse período, tenho realizado visitas esporádicas à cidade - para continuar a pesquisa de campo e, ao mesmo tempo, rever amigos e conhecidos. Essas e outras experiências fazem parte da minha convivência com brincantes e encantados, e foram também incluídas neste artigo. Elas permitem perceber os efeitos da passagem do tempo e as transformações na vida dos meus interlocutores nos últimos anos. O texto se constrói em torno da trajetória de Luiza, mas trata, igualmente, de elementos vividos por outros pais e mães de santo da localidade.

3 Os terecozeiros (ou "brincantes") afirmam que um mesmo encantado, recebido por duas pessoas diferentes, pode se comportar de forma diversa, pois essa é uma de suas capacidades ou habilidades. 4 A Secretaria de Cultura e Igualdade Racial da Prefeitura Municipal de Codó (criada em 2009) estima que existam, no município, um número aproximado de 200 tendas. A Associação de Umbanda, Candomblé e Religiões Afro-brasileiras de Codó e Região realizou um levantamento sobre a quantidade destes locais e afirma que existem 294 tendas e 109 quartos de santo na cidade. 


\section{TRANSFORMAÇÃO E PESSOA}

No terecô, um brincante recebe, durante sua vida ou mesmo durante uma noite de tambor, diversas entidades. Não é incomum que ele não saiba dizer o número exato de seres que ocupam seu corpo, pois alguns deles se manifestam raramente ou de passagem - na incorporação, um corpo que se abre se torna vulnerável a presenças diversas. Em outros momentos, é difícil reconhecer um encantado, haja vista a possibilidade de ele se "apresentar" de maneiras muito dissemelhantes, confundindo as pessoas e mantendo seu nome desconhecido.

Outros encantados, entretanto, se manifestam durante grande parte da vida de um sujeito, acompanhando o passar dos anos e participando de momentos fundamentais da trajetória de famílias - quando podem ser vistos fazendo, por exemplo, partos, aproximando casais, participando de funerais de entes queridos e demarcando espaços nos ambientes domésticos (Ahlert 2013)..$^{5}$ Alguns, inclusive, transitam entre diferentes gerações de uma mesma família, sendo recebidos como herança diante da morte ou do envelhecimento de alguém. Nesses casos, as pessoas que acompanham um pai ou mãe de santo durante anos convivem e criam relações também com os seus encantados, pois dialogam com eles, os reconhecem e, em diversos casos, contam com seu auxílio.

As relações entre as entidades e o/a terecozeiro/a que as recebe são a preocupação central deste texto e surgem em diálogo com diversas outras discussões da antropologia. A possibilidade da permeabilidade das fronteiras corporais ou mesmo a capacidade da extensão de um sujeito são aspectos que, há décadas, chamam atenção de antropólogos interessados na compreensão da racionalidade e do pensamento, do indivíduo e da pessoa. Nessa perspectiva, Lucien Lévy-Bruhl (2008 [1922]) sugeriu formas de conhecimento e ação onde a contradição não se apresentava como fundamental na definição do que seria uma pessoa. Maurice Leenhardt (1971) demonstrou a possibilidade de distinção entre a noção de eu e o corpo, configurando outra compreensão de pessoa e de mundo.

Igualmente, na antropologia contemporânea, a discussão sobre pessoa e, de forma concomitante, a percepção da não oposição entre sujeito e objeto; animal e humano, entre outras dicotomias questionadas (Strathern 2006, 2014; Ingold 1995; Haraway 2013), destacam o caráter compósito das pessoas e a importância das relações e conexões (Strathern 2006; Pina-Cabral e Silva 2013; Goldman 1984, 1987). Nos estudos sobre o que se convencionou chamar de religiões de matriz africana, religiões afro-brasileiras ou afro-americanas (Bastide 2001; Barros e Teixeira 1989; Espírito Santo 2010; Rabelo 2014), essa discussão tem espaço importante por chamar atenção para noções de pessoa particulares - que falam sobre corpos não fechados, identidades não

5 Quando, por exemplo, pedem a construção de quartos em sua homenagem ou têm seus objetos guardados em espaços específicos das casas. 
substantivas e possibilidades de participação - pois destaca as relações cultivadas entre pessoas e entidades (ou humanos e deuses, espíritos, etc.).

Em Codó, é no constante investimento no contato com as entidades que pais e mães de santo adquirem conhecimento para exercer sua função. Semelhante a outras religiões afro-brasileiras, como o candomblé angola, descrito por Goldman (2005), também um terecozeiro compreende que "[...] é inútil esperar ensinamentos prontos e acabados de algum mestre e que deve tratar de ir reunindo pacientemente, ao longo dos anos, os detalhes que recolhe aqui e ali" (Goldman 2005: 109). Entretanto, se compreende que todo o conhecimento e habilidade provêm dos próprios encantados e chegam aos pais, mães e filhos de santo na medida em que eles se comprometem com essas relações. É esse engajamento que os torna pessoas "sabidas", procuradas para diversos trabalhos e alívio de angústias.

A intensidade da presença dos encantados vai sendo cultivada desde as primeiras manifestações dos mesmos na vida de uma pessoa, quando uma relação vai sendo construída e desenvolvida no tempo (Rabelo 2008), ainda que não de forma linear. A aproximação e a afinidade não são dadas de partida, mas produzidas em momentos onde a "interaction is crucial for a reciprocal learning process" (Cunha 2013: 153). Para que essas relações aconteçam, devem ser cumpridos tabus e realizadas atividades como rezas, oferendas, trabalhos e festejos - resultado dos pedidos e da negociação com os encantados. Nesse sentido, se compreende que o poder de um pai ou mãe de santo (sua "força") é fornecido pelos seus encantados e é proporcional à dedicação à religião, às promessas e aos tabus que cumprem, às oferendas que apresentam. Desta forma, quanto mais um mestre trabalha (ou quanto mais interage com as entidades), mas expedito ele se torna.

Para pensar a pessoa no terecô, me parece possível afirmar que se fala de uma pessoa "múltipla, plural, expansiva, conectada" (Espírito Santo 2010: 498), de forma que:

“o que existe entre o médium e eles [espíritos] melhor se compreenderá como um projeto contínuo de pessoa em construção - os seres de ambos jamais se encontram em estado fixo ou imutável, mas se nutrem congruentemente um do outro, especificando-se na prática e numa aprendizagem de si, ao longo do tempo" (Espírito Santo 2010: 517).

Não há, portanto, uma pessoa acabada, mas em constante transformação. Isso se torna ainda mais evidente em algumas considerações que teço neste texto sobre as primeiras aproximações com as entidades, mas surge também em suas despedidas. Esse caráter transformacional daquilo que se é se desenrola na trajetória dos sujeitos e não significa afirmar que as pessoas se misturam com os encantados, mas que ambos se afetam mutuamente, tornando impossível a 
compreensão da vida das pessoas isolada da presença das entidades (Cardoso 2007). Essa presença, entretanto, não se resume a seu aspecto mais evidente - a possessão ou incorporação (Cruz 2014) -, mas se mostra no corpo, que, como vou sugerir ao término do texto, é consumido e passa a expressar a relação com os encantados para além dos momentos de possessão.

\section{NAS SAIAS DO ENCANTADO}

Quando conheci Codó, Luiza já vivia na cidade há mais de três décadas. Nascida na roça, ela havia, durante a vida, "feito de um tudo": quebrou coco babaçu, limpou terrenos, vendeu laranja em festa religiosa, plantou, costurou, criou três filhos. Em meio a todas essas atividades, ela também se tornou mãe de santo e por isso possuía, no espaço imediatamente contíguo à cozinha de sua casa, uma tenda de terecô. A Tenda Espírita de Umbanda Santa Helena ${ }^{6}$ - seu nome oficial - era (em sua parte visível ou tangível) um recinto pequeno, cuidadosamente decorado com bandeiras, altares, fitas e desenhos. Foi se constituindo e se transformando com a passagem do tempo, pois, tal como aconteceu com os barracões de outros pais e mães de santo da cidade, o de Luiza começou "humildezinho" e cresceu com a colaboração de encantados e pessoas (filhos de santo, clientes, visitantes e parentes).

Esse contar sobre o início das tendas sempre me parece prazeroso aos pais e mães de santo - visto que, embora destaquem o caráter árduo do passado, o estágio atual das tendas (mesmo as pequenas, como a de Luiza) atesta seu trabalho e seu compromisso. Essa dedicação se torna evidente na substituição das paredes de palha e barro por paredes de tijolo ou na decoração para os festejos anuais que realizam. A constituição das tendas de pais e mães de santo do terecô é, em alguma medida, homóloga à sua trajetória ou percurso na chefia desses espaços. Também eles começam sem notoriedade e sem filhos. Também eles só se tornaram o que são a partir da colaboração de diversas agências, como esboçarei na sequência do texto.

De forma semelhante a outros contextos etnográficos de pesquisa sobre religiões afro-brasileiras (Goldman 2009; Sansi 2009; Opipari 2009; Cunha 2013; Rabelo 2014), as narrativas sobre as primeiras manifestações das entidades (ou os primeiros sinais de "mediunidade") ocupam, no terecô, um lugar de muita importância. ${ }^{7}$ Em campo, não é incomum ouvir o contar de delicadas

6 A denominação "tenda espírita de umbanda" foi assumida pela maior parte dos pais de santo, independentemente de terem orixás, caboclos ou encantados como "chefes de croa" (donos da cabeça). 7 O termo mediunidade é aqui utilizado em sentido diverso da denominação do espiritismo kardecista, para definir a possibilidade de alguém receber (incorporar) uma entidade. Outros termos como médium, espírito ou espiritismo também podem ser utilizados por terecozeiros, sem que remetam, diretamente, ao espiritismo kardecista. 
histórias em que, quando crianças, pessoas foram tomadas por entidades no meio da plantação, perdendo o controle do corpo e assustando quem os acompanhava. Ou ainda quando, ao receberem os encantados, quebravam objetos domésticos, rolavam no chão, desapareciam da vista dos familiares. Maria dos Santos, mãe de santo de 76 anos, conta que, ao desparecer após receber um encantado, foi encontrada por seu irmão em uma gira de tambor:

"Ele [o irmão] chegou p'ra lá e me encontrou. Diz que eu era a mais pequena no meio. Dançando, dançando. Aí ele quis assim, um tipo de ignorância, quis me arrancar de dentro de lá, mas o pessoal não deixou. E quem estava comigo [a entidade], disse 'eu vou na hora que eu quiser, o senhor não me manda. A menina é minha, quem manda nela sou eu' " [Maria dos Santos, 10 de agosto de 2011].

A capacidade dos encantados de tomar sujeitos para si, interferindo em suas vidas, apresenta sinais variados, como dificuldades de visão, sonhos estranhos, confusão mental, loucura, doenças diversas não descobertas por médicos. Nas histórias que conheci, essas manifestações surgiam em torno dos sete, oito anos de idade e, por caminhos diversos, levavam ao diagnóstico de "problema com encantado". Esses caminhos falam sobre as particularidades da vida de cada pessoa e incluem a aceitação ou a recusa da família, a busca de soluções às aflições junto a médicos, benzedeiras ou rezadores.

Luiza lembra que, quando criança, via "espíritos" que a convidavam para brincar. Ela subia em árvore e rolava no chão, imitando esses seres e fazendo disso suas brincadeiras. A mãe Chiquinha - sua avó, que a criou desde que nasceu - não entendia o que se passava com a menina, "porque não tinha essas coisas de espiritismo lá" e a recriminava violentamente. Aos 14 anos, Luiza se casou com um primo e passou a residir em um povoado no interior de Codó - antes, vivia na região do Parnaíba, fronteira com o Piauí. Depois do casamento, as aflições relacionadas à sua mediunidade apareceram com maior intensidade e os encantados, que antes vinham para brincar, agora a faziam sumir durante dias, "correndo louca" dentro das matas na zona rural. O marido então reunia trabalhadores da roça para saírem à procura de Luiza e a trazerem de volta para casa.

Como na história de Luiza, existem casos de brincantes que não frequentavam tendas quando crianças. Outros, por sua vez, eram levados por familiares, de forma esporádica, para festas de tambor, pois em suas famílias existiam pessoas com "mediunidade". Seu João Tavares, pai de santo de 78 anos, acompanhava sua avó em festas de tambor que eram realizadas nas roças da cidade. Foi em sua companhia que recebeu um encantado pela primeira vez. Pedro de Oxum, também pai de santo, acordava com a saída do avô de casa durante a noite e o seguia pelas ruas da cidade até alguma tenda. Carregado pelas entidades dentro de suas saias, ele entrava nas giras dentro dos salóes e só 
então era percebido. Com a morte do avô, Pedro recebeu sua principal encantada e começou a fazer curas e rezas.

Nessas experiências vividas na infância, o mais comum é, na impossibilidade de ignorar as manifestações dos encantados, buscar "suspender as correntes", retardando o envolvimento com a religião. Essa suspensão é feita com a ajuda de chefes de tendas, procurados e consultados por pessoas próximas à criança. Eles negociam com os encantados o desaparecimento temporário das suas manifestações, as tornando presentes apenas quando a criança já estiver mais velha. Na negociação, compromissos são assumidos pela família do brincante, que podem incluir auxílio financeiro com o material dos rituais da casa, a realização de rezas e homenagens às entidades, e o agendamento de idas esporádicas à tenda.

Apesar das variações no que concerne as primeiras manifestações dos encantados, a "mediunidade" é vista como "de nascimento" e se entende que é praticamente impossível se livrar dela. Desta forma, passado algum tempo, os encantados voltam a se manifestar no cotidiano das pessoas. É preciso então reconhecer a sua presença, perguntar o que desejam e aprender a controlar o corpo quando eles descem ou sobem. Esse processo inicial, marcado pelo desconhecimento e mesmo pelo desinteresse em relação aos assuntos do terecô, não raro é vivido por intermédio de constrangimentos causados pelas entidades - que fazem as pessoas subirem em árvores sem conseguir descer, correrem longas distâncias, tirarem roupas e acessórios que carregam consigo.

Nas trajetórias que conheci, existem duas formas de aproximação com os encantados. Por um lado, há pessoas que “já nascem preparadas” e não precisam de nenhuma iniciação - o que Sansi (2009) considera, em outro contexto, sobre o dom. Por outro lado, existem os casos em que se conta com a mediação de algum pai ou mãe de santo mais experiente. Nessas situações, no terecô, não existe uma iniciação única e necessariamente marcada pela presença do neófito em um terreiro. O próprio termo "iniciação", comum em diversas etnografias sobre religiões afro-brasileiras, é pouco usado na cidade - talvez com exceção de pais de santo com envolvimento com o candomblé. Em Codó, o que se coloca é uma "preparação" - um termo polissêmico que remete a diferentes experiências de aproximação a uma tenda. O período de "preparação" de um brincante é determinado a partir dos encantados que ele recebe e dos ditames dados pelas entidades do pai de santo da casa. Como o terecô foi, algumas vezes, comparado ao tambor de mina de São Luís, especialmente com a Casa das Minas, onde a iniciação foi vista como extremamente complexa e, de certa forma, seletiva (Eduardo 1948, revisitado por Bastide 1971; S. Ferretti 1996), o ingresso dos brincantes nas tendas de Codó foi percebido como pouco sofisticado, simples e mesmo "pobre".

No ingresso em uma tenda, o futuro filho de santo deve realizar diversas obrigações, manter tabus, passar por banhos de purificação, entre outras atividades 
e normativas fornecidas pelos encantados. Esse período de "preparação" conta com a participação do pai de santo, que acompanha por algum tempo o recebimento dos encantados e conversa com eles. Esse processo de reconhecer entidades e "organizá-las" faz pais e mães de santo conceituarem o ingresso de um novo filho em uma casa como algo muito trabalhoso. Isso acontece porque, a partir da "preparação", pais e filhos de santo estão conectados, pois suas ações afetam a "força" de uma tenda e mesmo a saúde de cada um deles.

Como percebeu Rabelo (2014) para o candomblé keto, em Salvador, no terecô as entidades ou os encantados são também agentes no processo de aprendizado de um neófito. Considera-se que o saber vem das entidades, de forma que o terecô é algo que se aprende "fazendo", a partir do momento em que é afirmada a aproximação entre uma pessoa e um encantado. Esse conhecimento, entretanto, nunca é totalizante ou absoluto - sempre se sabe muito pouco e não se conhece necessariamente a razão de tudo o que deve ser feito. O mérito do saber utilizado pelos pais e mães de santo é, portanto, dos encantados, provém da relação com eles.

"Ele [o pai de santo] só fez assim, preparou nós, quando chegou um dia ele mandou cada um de nós chamar o nosso guia, depois que chegou e baixou ele disse: 'Agora, seu Zé, você vai se virar com os seus guias, você vai cuidar dos seus guias... Você vai zelar por ele, nem p'ra mim, nem p'ra ninguém'. Então, se nós sabemos um pouquinho, é os nossos guias que dão tudo" [Zé Preto, 28 de agosto de 2011 ].$^{8}$

No momento em que começou a sofrer diversas intervenções das entidades, Luiza passou a frequentar a casa de um mestre, perto do povoado onde vivia. Durante toda sua vida, guardou muito respeito à sua pessoa e sua casa. Apesar disso, considera que o início de sua experiência enquanto médium foi muito solitário. Seus companheiros foram os encantados e um grupo de árvores que, com o passar do tempo, ensinaram-na o que sabe sobre a encantaria. Um pé de pitomba, um de violeta e um de jatobá, próximos da casa onde vivia, a ensinaram a fazer curas e atendimentos. Sempre que era procurada, ela consultava as árvores, acendendo uma vela em frente a cada uma delas para ouvir os seus conselhos. Em seguida, Luiza colocou uma "mesinha" de cura e passou a ser conhecida nas proximidades de sua residência por causa das aflições que, com seus encantados e suas árvores, resolvia. Já na cidade de Codó, no início dos anos 80 , construiu sua tenda.

Construir um quarto de santo, um salão ou tenda é "assumir a responsabilidade" - momento fundamental da trajetória de um mestre, quando adota 
de forma clara e direta as incumbências dadas por seus encantados. É um ato que transcende a mera edificação de um espaço para trabalhos, rezas e festejos, pois com ele se institui um novo status: o brincante que possui uma tenda se torna um pai ou mãe de santo. 9 "Colocar barracão" marca um novo momento da relação com as entidades e é também uma ação direta sobre as aflições que afetam a saúde dos terecozeiros, resultado da ação dos encantados. ${ }^{10} \mathrm{~A}$ partir desse momento, aumentam as atividades relacionadas aos mesmos e também a "força" que eles proporcionam ao pai ou mãe de santo.

Não é incorreto dizer que, na medida em que são assumidas essas responsabilidades pelos brincantes, também os encantados se transformam na relação que constroem com seus "cavalos" - como podem ser denominados aqueles que os recebem. Luiza, por exemplo, afirmava que só construiu sua tenda depois que os encantados concordaram com a condição, por ela estabelecida, de que eles não lhe causariam constrangimentos durante os seus trabalhos como mãe de santo. Igualmente, em outro momento, negociou com um encantado que, quando ele fosse recebido, ele não deveria beber - hábito que lhe era caro -, já que ela, "pura" (ou seja, sem receber a entidade) não bebia. Além de falar de uma transformação que pode ser bilateral, as histórias sobre a aproximação às entidades falam dos processos de agenciamento e desagenciamento (Rabelo 2014; Johnson 2014) que marcam as relações entre entidades e pessoas.

\section{NOS CADERNOS DO ENCANTADO}

Embora em campo seja recorrente ouvir histórias sobre as primeiras manifestações dos encantados na trajetória de brincantes, grande parte dos pais e mães de santo com quem convivi em Codó vivia um momento diferente. Eles já possuíam anos na chefia de suas tendas e muitos já haviam trabalhado na companhia (ou presença) dos seus encantados. Alguns mestres, com idades em torno de 70 anos, mencionavam aspectos relativos à "pesada" função que desempenhavam. Afirmavam o desejo de se afastar dos seus postos, diminuindo as atividades de seus salóes e o atendimento aos clientes. Essa segunda parte do texto trata desses afastamentos e discorre sobre uma transformação na concepção dos sujeitos sobre si.

Durante a pesquisa de campo, eu tive a oportunidade de conhecer alguns dos encantados de Luiza. Com Seu Bambu Verde (o nome conhecido de seu

9 Pode haver pais de santo que ainda não possuem salão, como no caso de Pedro, que recebe e trabalha com seus filhos de santo nos quartos de sua casa.

10 Algumas pessoas relacionam a melhora da saúde com a construção de suas tendas. Neste sentido, a mãe de santo Dona Jesus de João Marabaia me disse que, se não fizesse seu barracão, "Eu iria ficar doida do meu juízo. Eu sonhava sempre e construir aqui foi como tirar um peso das minhas costas" (maio de 2011). 
chefe de croa), Seu Duardo Légua e Sebastiãozinho (uma criança) convivi com maior frequência, pois compareciam sempre que havia alguma gira, tanto na casa de Luiza quanto fora dela. Eles eram conhecidos de todas as pessoas que frequentavam, ainda que esporadicamente, a casa da mestra. Vi outras entidades da mãe de santo apenas em rituais com objetivos específicos (como a cura) ou em passagens rápidas (ao final de um tambor, por exemplo).

Há anos, Luiza recebia um encantado chamado Ernesto (ou Dom Ernesto). Segundo me contou, Ernesto era um senhor velhinho e muito sabido que, consultado nos trabalhos (especialmente de cura), era inquirido sobre o atendimento aos clientes. Em situações de consulta, seu diagnóstico era escrito, por ele mesmo, em um caderno. Quando, depois de uma sessão, a mãe de santo retomava a consciência, era seu marido, que sabia ler (conhecimento que Luiza não possuía), quem lhe dizia o que Ernesto anotara no caderno. Depois que o marido morreu, a própria Luiza conseguia entender as anotações do encantado, com quem ainda trabalhou alguns anos, até que ele se despediu e "não veio mais".

A incorporação, no terecô, é entendida como perda da consciência - um deslocamento do médium, como "se ele estivesse dormindo" - e, por isso, Luiza disse que nunca soube onde os cadernos de Ernesto ficavam guardados. Ela acreditava que eles eram depositados em um lugar conhecido apenas pelas entidades. Há cerca de sete anos, sem querer, ela os encontrou em sua casa. Mexendo nas páginas e lendo o que compreendia, se recordou de uma grande quantidade de pessoas que, com seus encantados, havia acompanhado e atendido. Segundo me contou, percebeu - ao ler nomes e situações de consulta que muitas das pessoas ajudadas passavam em frente à sua casa, mas não mais conversavam com ela, nem agradeciam o trabalho realizado. Ao constatar a ingratidão das mesmas, sentiu que "era como se eu tivesse ido embora da terra. Como se eu tivesse saído do meu corpo, numa agonia muito grande" (diário de campo, 17 de maio de 2011). Depois do episódio, os cadernos de Ernesto voltaram a desaparecer. Luiza não sabia o que havia acontecido com eles, mas acreditava que algum de seus encantados, em fúria, se desfez dos mesmos. O encontro com os escritos do encantado, porém, desencadeou uma importante tomada de decisão: Luiza percebeu sua intenção de parar de trabalhar como mãe de santo.

Evidentemente, o efeito causado pelos cadernos encontrou ressonância numa miríade de sentimentos que faziam parte da trajetória de Luiza e que, em alguma medida, eram compartilhados por outros pais e mães de santo. Esses sentimentos acompanhavam percepções positivas sobre a chefia das tendas (como a beleza das festas, o prazer em homenagear entidades e ajudar pessoas), mas eram uma espécie de outro lado - inevitável - da moeda: a tristeza da falta de reconhecimento e o esquecimento, o cansaço e as diversas dores no corpo causadas pelas atividades, o envelhecimento. Luiza utilizava 
continuamente o discurso do esquecimento e da ingratidão como elementos fundamentais para sua tomada de decisão. Iracema, mãe de santo com idade semelhante à de Luiza, também usava os mesmos argumentos, dizendo ainda que cuidar de um salão era uma atividade desgastante e exigia uma dedicação muito grande, por isso, embora mantivesse seus festejos, não aceitava novos filhos de santo. Maria dos Santos, herdeira de uma tenda muito importante no âmbito da religião da cidade, ainda que tivesse uma rotina muito ativa, se utilizava de termos semelhantes para demonstrar o momento em que vivia, marcado por dificuldades físicas e pelo "peso" do trabalho com o terecô.

A decisão de parar de trabalhar não depende apenas de um mestre, ou seja, do desejo de Luiza, pois está sujeita à negociação feita com seus encantados. Por intermédio de rezas, de alguma oferenda ou por comunicação em sonhos, por exemplo, os encantados são consultados sobre procedimentos como a diminuição dos toques de tambor de uma casa, a não aceitação de novos filhos de santo, a recusa às demandas dos clientes e dos familiares. Além disso, pode-se perguntar sobre o fim de uma festa em homenagem às entidades e o despacho dos elementos que compõem uma tenda - como as pedras onde encantados estão assentados, imagens de santo que compõem um altar, objetos de uso de cada encantado, etc.

Luiza, em conversa com as entidades de sua casa, reduziu a periodicidade dos toques de tambor até que, em 2014, praticamente deixou de realizá-los, mantendo apenas uma reza semanal e a festa de sua tenda. Há algum tempo, não mais aceita novos filhos de santo, acompanhando apenas nove mulheres que dançam com ela há anos. ${ }^{11}$ Igualmente, não faz mais trabalhos de cura ou tratamento considerados difíceis - recusou, por exemplo, o pedido de uma vizinha que gostaria que ela diagnosticasse e tratasse uma de suas netas. Mantém uma rotina de rezas e as velas dos seus altares acesas e, no mais, sentada nos pequenos bancos em frente à sua casa, resta-lhe benzer os passantes e as crianças - uma atividade considerada de pouca complexidade e poder. Algumas vezes, lamenta ter de dispensar pessoas que, em outros momentos de sua trajetória, teria podido ajudar.

Quando um pai ou mãe de santo diminui as atividades que faz na chefia de uma tenda, seu poder e eficácia são reduzidos. Como se compreende que a "força" provém dos encantados - sendo uma "transferência de poder ou agência" (Sansi 2009: 144) -, para ser forte é preciso participar ativamente de um sistema de prestações, contraprestações e homenagens, que inclui consultas, trabalhos e festas. Logo, quando um mestre negocia a diminuição das suas atividades, ele também trata da redução gradual de sua "força" ou da energia proveniente das entidades. Isso quer dizer que, nestas situações, o pai ou mãe 
de santo fica com um poder de ação diminuído e, portanto, não pode mais “ajudar" os outros como antes. É uma presença mais vulnerável e é preciso, pois, reinscrever-se de outra forma no mundo (Vianna 2014) - com capacidades e habilidades transformadas.

As mudanças pelas quais a vida de Luiza como mãe de santo passara, entretanto, não eram apenas uma redução de tarefas e responsabilidades. Elas também configuram um afastamento em relação aos encantados, pois a diminuição das atividades associadas aos mesmos significa um arrefecimento de suas presenças. Como procurei enfatizar no início do texto, no desenrolar da vida dos pais e mães de santo, esses vão, paulatinamente, construindo e reforçando as suas relações com as entidades (Goldman 2009; Sansi 2009). Essas relações se dão por intermédio da incorporação - quando o encantado ocupa o corpo do brincante -, mas também no cumprimento das obrigações, nos trabalhos aceitos, nas rezas realizadas (ou seja, em diversos elementos e momentos além da incorporação). Se compreendermos que as entidades são parte da pessoa, a intensidade do sofrimento no seu afastamento fala também de uma despedida que, em alguma medida, é a de si próprio. Ou seja, quando um pai ou mãe de santo decide "aposentar-se" das funções de chefia de uma tenda, ele toma uma decisão que em nada é leviana ou simples, mas que desencadeia diversas experiências, muitas delas de sofrimento.

Essas transformações, vividas pelos mestres, também são sentidas pelas pessoas que frequentam os salóes. Por um lado, essas pessoas podem incentivar a diminuição das atividades de uma tenda quando percebem que pais e mães de santo estão muito cansados ou envelhecidos. Paralelamente, entretanto, falam sobre a ausência das entidades, deixando evidentes as saudades que sentem: ${ }^{12}$ nostalgicamente relembram as festas antes realizadas pela casa, a quantidade de pessoas que as frequentavam. Esses lamentos evidenciam algo que me parece ser fundamental na trajetória de um chefe e na constituição de uma tenda: a importância das relações sociais - das quais participam pessoas e entidades. Nesse sentido, o "aposentar-se" da função de pai ou mãe de santo é uma transformação de si (do saber, das capacidades), na igual medida em que é uma diminuição das alianças e das relações sociais.

\section{NO CORPO DE “MOÇA VELHA”}

Em setembro de 2014, estive em uma gira na casa de Luiza. Naquele momento ela já não tocava tambor regularmente e sentia intensas dores nas costas. Suas filhas de santo dançavam, de forma esporádica, em outras casas. No final do evento realizado na tenda, Sebastiãozinho, o encantado-criança recebido pela 
mãe de santo, ficou conversando conosco sobre a condição física dela. Disse-nos que sabia que ela andava com muita dificuldade e que algumas vezes não conseguia se levantar quando estava sentada. Provocando, ergueu-se e se sentou várias vezes, dizendo ser esse um problema da mãe de santo e não dele, que era jovem. Continuando a brincadeira, fez uma dramatização que imitava a forma com que ela ficava de pé com dificuldade. As pessoas presentes riram das peripécias do encantado, mas insistiram que ele deveria aconselhar Luiza a procurar um médico, já que ela se recusava a tomar remédios e fazer acompanhamento do seu problema na coluna. O encantado não deu muita atenção aos pedidos, se divertindo com as brincadeiras que realizava para a plateia atenta aos seus feitos.

Tal como Sebastiãozinho, quando se fazem presentes nos corpos de brincantes, os encantados podem reclamar ou fazer brincadeiras com a condição física dos mesmos, dizendo, por exemplo, que eles, sendo novos, precisam se sujeitar a vir "em moça velha" - ou seja, em uma pessoa idosa. ${ }^{13}$ Esboçam ameaças, dizendo que vão deixar os corpos cansados quando "subirem" e que vão "judiar" do corpo velho que os recebe. Nesse sentido, como relatam outros pesquisadores, ao serem recebidas, as entidades têm a possibilidade de experimentar a corporalidade (Carvalho 1994; Neto 2012; Birman 2005) e acrescentar novas dimensões a ela, mostrando, a partir da postura corporal, como sua presença altera as condições do corpo de seu "cavalo".

Nas experiências que tenho compartilhado neste texto, o corpo tem lugar central. Ele é ocupado pelas entidades em diversos momentos do terecô, que o tomam para dançar e trabalhar, que o embalam rapidamente ao som dos tambores, que o giram continuamente. Além da dança, as entidades tomam corpos e com eles saúdam conhecidos, benzem visitantes, pagam penitência em frente aos altares ou aos pés de outros encantados. Como resultado de suas vindas e de sua presença, manchas e cicatrizes surgem e permanecem nos corpos dos terecozeiros, mesmo quando as entidades não estão presentes. Dona Concita, uma senhora já idosa, explicava as manchas nas mãos e braços como resultado dos inúmeros partos que seu encantado - "em cima dela" - havia feito, sem o uso de nenhuma proteção. Semelhante marcação do corpo acontecia com Luiza que, desde que começou a negociar com os encantados a diminuição das atividades de sua tenda, sentia que um dos seus braços não tinha a funcionalidade de antes. Ele perdera a força e a flexibilidade, se tornando cada vez menos útil. Para ela, a debilidade que acometia essa parte de seu corpo era um

13 Nessas formas de compartilhar os corpos, os encantados não apenas transformam as pessoas como são transformados pelas experiências que vivem com elas. No terecô compreende-se que as diversas entidades têm uma cronologia diferente dos humanos - ou seja, que a contagem de anos para estes seres é diferente. Conquanto eu nunca tenha ouvido uma possível quantificação dessa diferença, entende-se que os encantados são seres ancestrais, mas também contemporâneos. 
sinal das entidades que entenderam que, já que ela não mais trabalharia, não precisava daquele braço funcionando perfeitamente.

A ação das entidades sobre os corpos - na possessão e para além dela indica outro elemento fundamental da relação entre os terecozeiros, especialmente os chefes de tenda, e os encantados. O corpo é um reflexo de uma compreensão mais ampla de que dançar terecô é algo "trabalhoso" (haja vista as obrigações, os tabus alimentares e a dedicação). Diante disso, o trabalho na função de pai ou mãe de santo é algo "pesado". Essa qualidade está associada com a necessidade de lidar com um conjunto de seres e seus desejos, assim como com pedidos de clientes, realizados em atendimentos e consultas. Ao realizar algum trabalho, resíduos desta operação sempre permanecem com o pai ou a mãe de santo. Esses resíduos, tal como são definidos pelos sujeitos, são energias ou forças ruins relacionadas com situações-foco dos trabalhos - como experiências de conflito ou de doença, por exemplo. Segundo me contou Dona Maria dos Santos, nem mesmo a utilização de rituais de purificação, como banhos de ervas, consegue aplacar totalmente essa negatividade.

Com o passar dos anos da vida de um pai de santo, os resíduos se acumulam em seu corpo e vão confluindo para sua fragilidade, para o acometimento de doenças, para o envelhecimento. Não que o cansaço, a velhice e os problemas de saúde não incidam sobre qualquer pessoa, independentemente de ser ou não pai ou mãe de santo, haja vista uma compreensão biologizante da passagem do tempo. Contudo, no caso dos mestres, a exposição ao "pesado" e ao "trabalhoso", a lida com o perigo e com diversas energias, a constante busca de equilíbrio e proteção alcançam uma intensidade não compartilhada por todos.

Muito embora qualquer trabalho pese sobre o corpo de pais e mães de santo, nem todos o afetam igualmente. Os mais onerosos são aqueles considerados os "trabalhos para o mal", termo utilizado para se referir às atividades voltadas à mediação de conflitos considerados sérios (que envolvem violência ou morte), mas nem sempre utilizado em sentido definido. Muitos dos chefes de tenda se recusam a fazer esses trabalhos, vistos como uma área de conhecimento que não é dominada por todos. "Para fazer o mal é preciso saber" era uma expressão usada para mostrar que eram poucos aqueles que possuíam habilidade suficiente para executá-los sem que isso resultasse na criação de infortúnio para si próprio. Doenças como o câncer e inchaços diversos poderiam ser sinais de má execução e da falta de proteção necessária na feitura de trabalhos com este perfil.

Entretanto, independentemente da natureza dos trabalhos, eles servem, genericamente, para "resolver problemas" e, neste sentido, são sempre pesados. Igualmente, manter uma tenda, perguntar às entidades o que desejam, conhecer os encantados de cada filho de santo (ou seja, prepará-lo), sempre envolve uma entrega considerada intensa. Podemos sugerir que, se as relações, a eficácia e a força de um pai de santo são resultado de seu engajamento e 
comprometimento com as entidades - quanto mais trabalha com os encantados, mais forte se torna (pois deles recebe a "força") -, é essa mesma dedicação que, paralelamente, vai consumindo seu corpo, sua saúde e sua vitalidade. O corpo, nesse sentido, mesmo sem a presença do encantado na possessão, é tomado pelas entidades em um sentido mais amplo (nas marcas, cicatrizes, doenças e desgastes).

Essa confluência de sentimentos relativos aos pactos estabelecidos entre pessoas e entidades conduz ao momento de diminuição das atividades de uma tenda, à “aposentadoria", ao afastamento das entidades e ao arrefecimento da eficácia de pais e mães de santo. Distanciar-se dos encantados por intermédio da diminuição das atividades de uma tenda também significa a redução das relações entre os mestres e outras pessoas - que, por exemplo, os procuram como clientes ou visitam suas festas. Há, portanto, algo muito sensível nesse momento de vida de pais e mães de santo, porque se coloca de forma mais evidente o risco da solidão - algo bastante temido pelas pessoas com as quais convivi em campo.

Entretanto, ao se retirarem de determinadas situações sociais, os mestres não necessariamente produzem rompimentos (Boschemeier 2015). Antes, tendem a incentivar que outras relações se estabeleçam. Luiza, por exemplo, quando procurada, indica a casa de outros pais e mães de santo, tanto para quem busca um local para dançar terecô, quanto para quem precisa de ajuda. Nesse sentido, ainda que sua tenda seja "fechada", ou seja, não tenha continuidade ${ }^{14}$ após o afastamento das suas atividades na chefia ou diante de sua morte, ela coloca outras pessoas em contato e em relação.

Igualmente, os encantados também podem contribuir para o estabelecimento de outras relações sociais. Aqueles que deixam de ser recebidos por uma pessoa - por causa de sua morte, velhice ${ }^{15}$ ou "aposentadoria" - muito provavelmente serão recebidos por alguém das suas relações de proximidade (Ahlert 2013). Não é incomum, por exemplo, casos como o de Pedro, que recebeu a encantada que era de seu avô, como mencionei no início do texto. Além de contribuírem para manter as relações sociais, as entidades também mantêm a lembrança das pessoas, ou seja, na medida em que são considerados seres ancestrais, mas também contemporâneos (pois se transformam e somam experiências às suas histórias de vida), sempre "carregam" consigo, naquilo que são, parte dos seus antigos "cavalos".

14 A tenda de Luiza não tinha herdeiro - nenhuma de suas filhas de santo fora preparada para continuar as funções de chefia da casa. Os encantados lembravam continuamente que elas não sabiam realizar diversas atividades, nem mesmo "benzer inocente". Elas temiam a morte da mãe de santo, pois compreendiam que ela "segurava" a saúde das mesmas e cuidava de cada uma delas. O fim da casa, entretanto, não era percebido por Luiza como deterioração ou necessário problema.

15 Existem relatos de um encantado da família de Légua Boji Buá, chamado Coli Maneiro, que tende a se afastar de seus "cavalos" quando eles envelhecem. 


\section{CONSIDERAÇÕES FINAIS}

Neste texto, tratei de questões que remetiam às relações entre pessoas e encantados, no âmbito do terecô, na cidade de Codó. Busquei considerar aqui relatos sobre as primeiras manifestações das entidades, quando aflições que incidem sobre a mente e o corpo dos sujeitos indicam a presença desses seres mais que humanos. Em um segundo momento, escrevi sobre as situações de afastamento entre uns e outros, especialmente no que concerne ao envelhecimento de pais e mães de santo - quando se percebe o desgaste e o consumo dos seus corpos e de sua saúde, e se busca o afastamento da chefia das tendas.

Se, como sugeri, é possível falar em modalidades de participação (Lévy-Bruhl 2008 [1922]) ou em pessoas plurais e compósitas (Strathern 2014; Pina-Cabral e Silva 2013) - que chamam atenção para uma presença dos encantados que extrapola os momentos de incorporação - essa perspectiva tem, pelo menos, dois momentos. No primeiro, a participação potencializa, garante "força" e poder aos pais e mães de santo, os tornando cuidadores e curadores daqueles que os rodeiam. Nele, as relações entre humanos e encantados intensificam também as relações entre as pessoas de uma forma mais ampla - entrecruzando, por exemplo, clientes, familiares, pais e filhos de santo. No outro momento, ou mesmo paralelamente, essa participação consome e exaure os corpos dos mestres, os debilitando com a passagem dos anos. ${ }^{16} \mathrm{Nas}$ situações de despedida e envelhecimento, quando os encantados vêm menos ou nem mesmo são recebidos, quando os clientes não mais aparecem, pois não recebem tratamento, ou quando se expressa a ingratidão e o esquecimento, vemos uma diminuição de relações em torno de um mestre. Esse momento se torna, em alguma medida, o oposto dos investimentos de toda uma vida, quando havia uma dedicação intensa aos encantados e pessoas. Quando se colocam à parte dessas relações, as mães e pais de santo, entretanto, mobilizam outras conexões, colocando as pessoas em contato com outras tendas e outros curadores.

O desequilíbrio constante e o caráter incompleto ou sempre em transformação - das relações, das pessoas, dos corpos, dos encantados e do conhecimento que marca o intensificar ou o arrefecer das relações, entretanto, não é tão linear quanto apresento no texto. Isso acontece porque existem negociações com as entidades (que têm agências e desejos) e em função das situações particulares vividas por cada pessoa. Na casa de Luiza, por exemplo, eu ouvia constantemente as falas sobre a ingratidão das pessoas, o desejo de fechar a tenda e o afastamento dos encantados. Todavia, em novembro de 2015 eu estive em

16 Coloca-se, durante o percurso de vida de um terecozeiro, um desequilíbrio do seu bem-estar, continuamente combatido por diversos procedimentos religiosos, mas também alimentado por eles, diferentemente de como a questão se coloca para Barros e Teixeira (1989), que indicam a importância do equilíbrio do corpo na noção de saúde no candomblé. 
sua casa, acompanhada de alguns dos meus alunos, quando um encantado anunciou sua chegada com o seu ponto de apresentação. Para minha surpresa, era Ernesto, entidade sobre a qual ouvi falar a respeito das curas, anotadas nos cadernos, e que tinha, segundo Luiza, se despedido há alguns anos. Perguntei à filha de Luiza quando ele tinha voltado. Ela me contou que fazia alguns meses, quando a nova bisneta de Luiza, de menos de um ano, esteve adoentada.

Ernesto, que acompanhou Luiza durante anos, mas não retornava há quase uma década, voltou para cuidar de sua bisneta em um momento em que ela quase não mais trabalhava na tenda. Ninguém sabia por quanto tempo ele permaneceria e, naquela noite, ele pouco nos contou sobre si. Entretanto, sua aparição permite-nos pensar nas conexões entre gerações de familiares e encantados. Essas conexões que se desenham, sob forma de parceria e retroalimentação, falam da complexidade sensível que é estabelecer uma vida - ou ter uma vida estabelecida - na companhia das entidades. Mostram como os afastamentos carregam sentidos de liberdade, mas também implicam em sofrimentos.

Etnografar a presença dos encantados - suas possibilidades de afeto e participação na vida das pessoas - implica levar a sério suas presenças e o impacto das mesmas na vida dos sujeitos (na incorporação e mesmo fora dela). As entidades, no caso dessa pesquisa em Codó, fazem parte do contexto e isso não apenas pelo fato de que é possível literalmente conversar com as mesmas, mas também porque impactam e interferem nas relações sociais nas quais, quando estamos em campo, também participamos. Há de se pensar que, em alguma medida, no contexto das práticas do terecô de Codó, nenhum brincante vive só. 


\section{BIBLIOGRAFIA}

AHLERT, Martina, 2013, Cidade Relicário: Uma Etnografia sobre Terecô, Precisão e Encantaria em Codó (Maranhão). Brasília, Programa de Pós-Graduação em Antropologia Social, Universidade de Brasília, tese de doutorado.

ARAÚJO, Paulo Jeferson Pilar, 2008, "Umbandização, candombleização: para onde vai o terecô?”, em Anais do X Simpósio ABHR/UNESP - Assis (2008), Associação Brasileira de História das Religiões, disponível em < http://www.abhr.org.br/wp-content /uploads/2008/12/araujo-paulo.pdf > (última consulta em maio de 2016).

BARROS, José Flávio, e Maria Lina TEIXEIRA, 1989, "O código do corpo: inscrições e marcas dos orixás”, em Carlos Eugênio Marcondes de Moura (org.), Meu Sinal Está no Teu Corpo: Escritos sobre a Religião dos Orixás. São Paulo, Edicon/ Edusp, 36-62.

BARros, Sulivan Charles, 2000, Encantaria de Bárbara Soeira: A Construção do Imaginário do Medo em Codó - MA. Brasília, Programa de Pós-Graduação em Sociologia, Universidade de Brasília, dissertação de mestrado.

BASTIDE, Roger, 1971, As Religiões Africanas no Brasil: Contribuição a Uma Sociologia das Interpenetrações de Civilizações. São Paulo, Pioneira.

BASTIDE, Roger, 2001, O Candomblé da Bahia: Rito Nagô. São Paulo, Companhia das Letras. BIRMAN, Patrícia, 2005, "Transas e transes: sexo e gênero nos cultos afro-brasileiros, um sobrevoo", Estudos Feministas, 13 (2): 403-414.

BOSCHEMEIER, Ana Gretel Echazú, 2015, Corpo de Planta: Terapias e Magias dxs Curiosxs da Baixa Amazônia do Peru, sob Uma Perspectiva Situada de Gênero e Saúde Popular. Brasília, Programa de Pós-Graduação em Antropologia Social, Universidade de Brasília, tese de doutorado.

CARDOSO, Vânia, 2007, "Narrar o mundo: estórias do 'povo da rua' e a narração do imprevisível”, Mana, 13 (2): $317-345$.

CARVALHO, José Jorge de, 1994, "Violência e caos na experiência religiosa: a dimensão dionisíaca dos cultos afro-brasileiros”, em Carlos Eugênio Marcondes de Moura (org.), As Senhoras do Pássaro da Noite: Escritos sobre a Religião dos Orixás. São Paulo, Edusp/Axis Mundi, 85-120.

CRUZ, Aline Torres Dias da, 2014, “Manipulando socialidades: 'pessoas', 'mistérios' e prestações rituais”, apresentado na 29. ${ }^{a}$ Reunião Brasileira de Antropologia, Natal.

CUNHA, Ana Stela de Almeida, 2013, "João da Mata family: Pajé dreams, chants and social life”, em Ruy Blanes e Diana Espírito Santo (orgs.), The Social Life of Spirits. Chicago, The University of Chicago Press, 123-158.

EDUARDO, Octávio Costa, 1948, The Negro in Northern Brazil: A Study of Acculturation. Nova Iorque, J. J. Austin Publisher.

ESPÍRITO SANTO, Diana, 2010, "Parcialidade e materialidade: a distribuição do ser e do saber no espiritismo cubano", em Maria Olívia Gomes da Cunha (org.), Outras Ilhas: Temporalidades e Transformações em Cuba. Rio de Janeiro, Aeroplano e FAPERJ, 493-548.

FERreTti, Mundicarmo Maria Rocha, 2000, Desceu na Guma: O Caboclo do Tambor de Mina em Um Terreiro de São Luís - a Casa Fanti-Ashanti. São Luís, Edufma (2. edição).

FERRETTI, Mundicarmo Maria Rocha, 2001, Encantaria de "Barba Soeira": Codó, Capital da Magia Negra? São Paulo, Siciliano.

FERRETTI, Sérgio Figueiredo, 1996, Querebentã de Zomadonu: Etnografia da Casa das Minas do Maranhão. São Luís, Edufma (2. ${ }^{\mathrm{a}}$ edição). 
GOldman, Marcio, 1984, A Possessão e a Construção Ritual da Pessoa no Candomblé. Rio de Janeiro, Programa de Pós-Graduação em Antropologia Social, Museu Nacional, Universidade Federal do Rio de Janeiro, dissertação de mestrado.

GOLDMAN, Marcio, 1987, "A construção ritual da pessoa: a possessão no Candomblé”, em Carlos Eugênio Marcondes de Moura (org.), Candomblé: Desvendando Identidades. São Paulo, EMW Editores, 87-119.

GOLDMAN, Marcio, 2005, "Formas do saber e modos do ser: observações sobre multiplicidade e ontologia no candomblé", Religião e Sociedade, 25 (2): 102-120.

GOLDMAN, Marcio, 2009, "Histórias, devires e fetiches das religiões afro-brasileiras: ensaio de simetrização antropológica", Análise Social, XLIV (190): 105-137.

GOLDMAN, Marcio, 2014, "Da existência dos bruxos (ou como funciona a antropologia)", R@u, 6: 7-24.

HARAWAY, Donna, 2013, Antropologia do Ciborgue: As Vertigens do Pós-Humano. Belo Horizonte, Autêntica.

INGOLD, Tim, 1995, "Humanidade e animalidade", em Revista Brasileira de Ciências Sociais, 28: 39-53.

JOHNSON, Paul, 2014, "Uma genealogia atlântica da 'possessão de espíritos'”, Translating the Americas, 2: 65-100.

LEENHARDT, Maurice, 1971, Do Kamo: La personne et le mythe dans le monde mélanésien. Paris, Gallimard.

LÉVY-BRUHL, Lucien, 2008 [1922], A Mentalidade Primitiva. São Paulo, Paulus.

NETO, Edgar Rodrigues Barbosa, 2012, A Máquina do Mundo: Variações sobre o Politeísmo em Coletivos Afro-Brasileiros. Rio de Janeiro, Programa de Pós-Graduação em Antropologia Social, Museu Nacional, Universidade Federal do Rio de Janeiro, tese de doutorado.

OPIPARI, Carmen, 2009, O Candomblé: Imagens em Movimento. São Paulo, Edusp.

PINA-CABRAL, João de, e Vanda Aparecida da SILVA, 2013, Gente Livre: Consideração e Pessoa no Baixo Sul da Bahia. São Paulo, Terceiro Nome.

RABELO, Miriam, 2008, "A possessão como prática: esboço de uma reflexão fenomenológica”, em Mana, 14 (1): 87-117.

RABElO, Miriam, 2014, Enredos, Feituras e Cuidados: Dimensões da Vida e da Convivência no Candomblé. Salvador, Edufba.

SANSI, Roger, 2009, “Dom e iniciação nas religiões afro-brasileiras”, Análise Social, 44 (190): 139-160.

STRATHern, Marilyn, 2006, O Gênero da Dádiva: Problemas com as Mulheres e Problemas com a Sociedade na Melanésia. Campinas, Editora da Unicamp.

Strathern, Marilyn, 2014, O Efeito Etnográfico. São Paulo, Cosac \& Naify.

VIANNA, Adriana, 2014, "Violência, Estado e gênero: considerações sobre corpos e corpus entrecruzados”, em Antônio Carlos de Souza Lima e Virginia García-Acosta (orgs.), Margens da Violência: Subsídios ao Estudo do Problema da Violência nos Contextos Mexicano e Brasileiro. Brasília, Associação Brasileira de Antropologia, 209-237. 